\title{
CORRECTION
}

Check for updates

Cite this: New J. Chem., 2021, 45,2830

DOI: $10.1039 / \mathrm{d} 1 \mathrm{nj} 90011 \mathrm{k}$

rsc.li/njc

\section{Correction: Spermine-directed supramolecular self-assembly of water-soluble AIE-active tetraphenylethylene: nanobelt, nanosheet, globular and nanotubular structures}

\author{
Duong Duc La, ${ }^{a}$ Jotiram N. Malegaonkar, ${ }^{\text {b }}$ Mohammad Al Kobaisi, ${ }^{\mathrm{c}}$ \\ Rajesh S. Bhosale, ${ }^{\text {b }}$ Sidhanath V. Bhosale ${ }^{\star b}$ and Sheshanath V. Bhosale ${ }^{\star d}$
}

Correction for 'Spermine-directed supramolecular self-assembly of water-soluble AlE-active tetraphenylethylene: nanobelt, nanosheet, globular and nanotubular structures' by Duong Duc La et al., New J. Chem., 2018, 42, 15379-15386, DOI: 10.1039/C8NJ02636J.

The authors would like to correct the XRD pattern of Su-TPE with the addition of 48 equiv. of spermine given in Fig. 7, which, in the published manuscript, is the same as the XRD pattern with the addition of 24 equiv. of spermine. The corrected Fig. 7 is shown below:

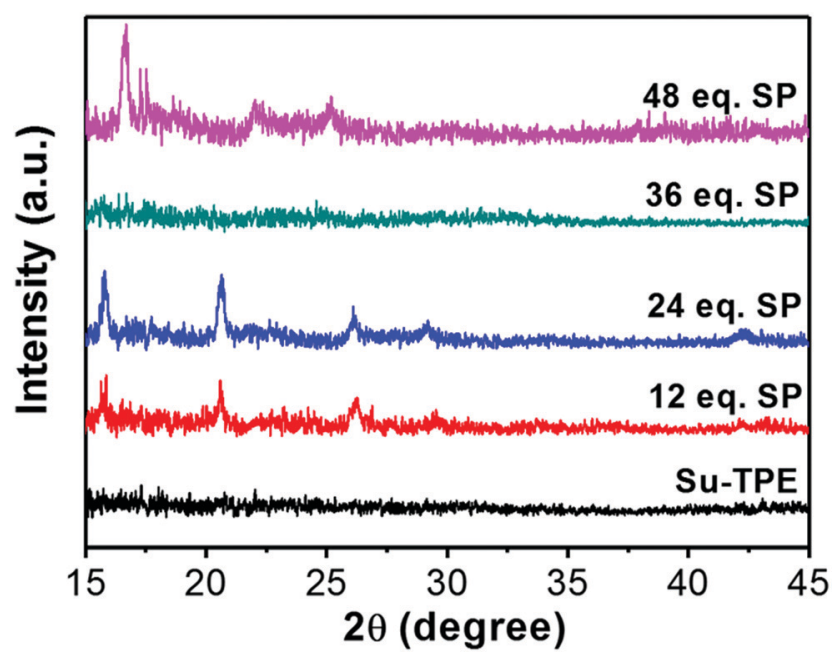

Fig. 7 XRD spectra of Su-TPE in THF:water solution $\left(f_{\mathrm{THF}}=95 \%\right)$ at $\mathrm{pH} 7$ upon addition of spermine $(12,24,36$ and 48 equiv. $)$.

The Royal Society of Chemistry apologises for these errors and any consequent inconvenience to authors and readers.

\footnotetext{
${ }^{a}$ Institute of Chemistry and Materials, 17 Hoang Sam, Cay Giay, Hanoi, Vietnam

${ }^{b}$ Polymers and Functional Material Division and Academy of Scientific and Innovative Research (AcSIR), CSIR-Indian Institute of Chemical Technology, Hyderabad 500 007, Telangana, India. E-mail: bhosale@iict.res.in ${ }^{c}$ Department of Chemistry and Biotechnology, FSET, Swinburne University of Technology, Hawthorn, VIC 3122, Australia

${ }^{d}$ Department of Chemistry, Goa University, Taleigao Plateau, Goa-403 206, India. E-mail: svbhosale@unigoa.ac.in
} 